\title{
LUULETAJAKS KUJUNEMINE
}

\author{
Liidia Tuulse 100
}

LIVIA VIITOL

$\mathrm{S}$ elle aasta 18. märtsil 100. sünnipäeva tähistav Liidia Tuulse (Haas) on oma põlvkonna hulgas ainus, kellest Rootsis ligemale kahekümne aasta möödudes 1944. aasta põgenemisest sai luuletaja. Liidia Tuulse ei ole kunagi kahetsenud, et luuletamine tuli tema ellu küpses eas. Oma kirjanduslikke kulgemisi alustas ta 1930. aastal noorteajakirjas Kevadik ilmunud Rabindranath Tagore luuletõlgetega ja ajalehes Postimees avaldatud reisikirjadega 1937. aastal. Luuletustega astus Liidia Tuulse lugejate ette 1961. aasta kevadel ajakirjas Tulimuld, esimene luulekogu „Liiv ja lumi” ilmus 1968. aastal.

Tuulse loominguline teekond sisaldab paljude märgilise tähendusega inimeste ning kohtade nimesid. Kohale ja paigale projitseeruvad ka inimsuhted ning koht on seotud oma „mina” otsingutega, ka luuletajaks saamisega. Kohakesksusest kõnelevad kõik Liidia Tuulse viis luuleraamatut, tosin ilmunud ning ilmumata proosapala, arvukad ajakirjanduses avaldatud reisikirjad ning ka päevikumärkmed.

Märgilise tähendusega kohtade alguspunktiks on Valga. Sinna asusid luuletaja ema ja isa elama Hummuli lähedalt Soe külast, kui Liidia oli kaheaastane. Kuueaastaselt Valga algkooli astunust sai kolm aastat hiljem Valga Tütarlaste Gümnaasiumi õpilane. 1980. aastate algul Bernard Kangro eestvõttel koostatud ning 1984. aastal Lundis ilmunud koguteoses „Koolilinn Valga” on lähemalt juttu Valga tütarlaste ja poeglaste gümnaasiumi õpetajatest, õpilastest ning koolide ühisüritustest. Kangro ja Tuulse lõpetasid gümnaasiumide humanitaarharud samal 1929. aastal. Kangro osales juba kooliajal õpilasajakirjade väljaandmisel, ka oma esimesed värsid saatis ta Eesti Koolinoorsoo Liidu luulevõistlusele Valga Poeglaste Gümnaasiumi abituriendina.

Koguteoses „Koolilinn Valga” tuleb juttu ka õpilaste omavahelisest suhtlemisest: sellestki, kuidas viimastes klassides tekkis poeg- ja tütarlastegümnaasiumi õpilaste vahel kooliteenija vahendusel salajane kirjavahetus (Koolilinn Valga 1984: 41-42). Ka Liidia Haas sai kirju: tundmatu noormees, kes kirjutas kirjadele alla „Van Straaten”, soovitas tal hakata koolis käima Kuperjanovi tänava kaudu, selgitades: „sest see on rohkem minu kandis”. Enda kohta teatab tundmatu kirjavahetaja: „Kui näete üht kentsakat poissi seal lonkimas, siis olen see mina" (Liidia Tuulse arhiiv). Kirjade vahetamine tekitas põnevust, kuni ühel päeval sattus kirjavahetus ootamatult tütarlastegümnaasiumi range direktrissi Marta Pärna kätte. Koguteoses „Koolilinn Valga” avaldatud kirjutises „Hapraid mälestuskilde VTG-st” kommenteeritakse juhtunut lähemalt: „Üks kiri loeti klassis avalikult ette... Ei seal ega teistes ei olnud ju midagi erilist. Tavalised laused... mõni õrnem sõna lõpus, mõni kohtuma kutse, mis iial ei toimunud. Sest... minu kirjapartneriks pol- 
nud mitte keegi vähem kui „Van Straaten”. Kes ta oli, ei saanud ma iialgi teada... veel vähem kohtasin teda..." (Koolilinn Valga 1984: 43). Mälestuskildude autoriks on sisukorras märgitud ladinakeelne Amicis audiuvantibus, Liidia Tuulse varjunimi.

Valga Tütarlaste ja Poeglaste gümnaasiumi lõpuaktus toimus 9. juunil 1929 poistegümnaasiumi saalis. Ühine teeõhtu peeti tütarlastegümnaasiumi saalis. Seal sündis otsus sõita järgmisel hommikul väiksema seltskonnaga Karulasse kevadist loodust imetlema. Rongis oldi eraldi vagunites, kokku saadi alles Karula jaamas. Noormehed peatusid Karula mõisas, neiud Kungla talus, kus elasid Liidia Tuulse sugulased. Nii Kangro kui ka Tuulse mälestuste põhjal oli kõige meeldejäävamaks sündmuseks retk Pikkjärve äärde ning Karula mõisnike matusepaika Kroodimäele (Tuulse mälestustes: Grothi mägi). Karula-sõidust on juttu ka Bernard Kangro mälestusteraamatus „Kipitai”. Seal öeldakse Kroodimäe kohta: „See jättis hooletusse jäetud koha mulje, nagu kõik sellised pärast sõda lahkunute rahupaigad. Mahasaetud puu oli mustast metallist ingli tiiva maha murdnud. (See Must Ingel jäi mind aastateks kiusama kui kaduva aja sümbol, kuni 30-ndail aastail sellest üritasin ballaadi kirjutada.)" (Kangro 1992: 156). Ballaad, mille Kangro kirjutas, on süngetooniline ja deemonlik. See kõneleb vannet murdnud noorest pruudiehteis neitsist, tammest, mis teda valvab, ja valge ingli mustaks muutumisest (vt Kangro 1990: 67-69).

Kolmkümmend aastat hiljem, 1966. aastal, kirjutas Kroodimäe mustast inglist luuletuse ka Liidia Tuulse. Tema luuletus on tagasivaateline, sellel on üllatuslik, Kangro ballaadi tasakaalustav lõpp (vt Tuulse 1997: 115; 2007: 241).

Enne sügise algust sai lapsehoidjana Pärnus viibinud Liidia Tuulse vanematelt teate õpingute jätkamise kohta Tartus. Ehkki Liidia esialgne plaan oli minna Tartusse alles järgmisel aastal - sõbratar Laine Klementil polnud varem selleks võimalust -, astus ta 1929. aasta sügisel Tartu Ülikooli filosoofiateaduskonda õppima saksa keelt ja kirjandust. 1933. aastal Eesti Naisüliõpilasseltsi liikmeks astudes kirjutab ta seltsile saadetud eluloos: „Mu lühikesed päikeselised alg[us]päevad ülikoolis lõppesid pea. Sõbratar, kellega olime tahtnud alata koos rünnakut teadusele, suri. Tulles taas Tartu ta surisängi veerest ja värske lillemere juurest, kuhu alla ta jätsin, algas aeg alul nagu unes, hiljem täis tööd, kus vältisin kõik rõõmud, mida olime koos kujutlenud." Tol esimesel ülikoolisügisel asus Liidia Tuulse saksa keele vahendusel tõlkima R. Tagore luuletusi. Need avaldati noorteajakirjas Kevadik.

Tartu Ülikooli filosoofiateaduskonda eesti keelt ja kirjandust õppima asunud ja esimesel Tartu-sügisel üliõpilasseltsi Veljesto liikmeks saanud Bernard Kangro tutvusringkond laienes ülikooli algusaastatel märgatavalt, Liidia Tuulse oma aga mitte. Oskar Kruus kirjutab: „Bernard jätkas Tartus luuletamist, kuid esialgu edutult - kuna teda avaldati harva, siis tundus ta ikka veel juhuluuletajana. Vahelduseks proovis ta proosat kirjutada ning pani paberile akadeemilist elu kujutava jutustuse noorest teoloogist ladinakeelse pealkirjaga „Liber memorialis cives academici”, mille saatis „Sädeme” novellivõistlusele. Sinna oodati aga naljalugusid, mitte psühholoogilisi etüüde. Kõrvalejäetud novelli käsikiri on säilinud ja viitab kriisiseisundile, mis Kangrol Tartu-aastate algul tekkis. Hiljem ongi elukogenud Kangro pihtinud, et ta selleaegsed värsikatsed olid täis spliini, pessimismi, nördimust ja hukkumise 
meeleolusid" (Kruus 2003: 24-25). 1931. aastal astus sõjaväekutse saanud Kangro Tallinna sõjakooli, tagasi Tartusse saabus ta 1932. aasta lõpul.

Liidia Tuulse stuudiumiaega saabus pööre 1933. aasta jaanuaris, kui Tartu Ülikoolis asus loenguid pidama Rootsist Tartusse õppejõuks tulnud kunstiteadlane professor Sten Karling. Germaani filoloogina valis Liidia Tuulse oma kohustuslikeks lisaerialadeks filosoofia, psühholoogia ja kunstiajaloo. Nii sattus ta Sten Karlingi loengutele. Seal sai ta tuttavaks kunstiajalugu õppinud Armin Tuulsega (Neumann). Liidia Haas ja Armin Tuulse armusid ning abiellusid kolm aastat hiljem, 1936. aastal. Ülikooli ajal süüvis Liidia Tuulse pedagoogikasse ning asus sel alal kirjutama ka magistritööd. 1937. aastal sõitis ta koos Armin Tuulsega Euroopa kunstivarade uurimisreisile: külastati Madalmaid, Itaaliat ja Saksamaad. Sel reisil hakkas Liidia Tuulse kirjutama reisikirju, kuid neid ajakirjanduses avaldades piirdus ta oma nime asemel eesnime esitähega.

Tartus oldud aeg kulus stuudiumile ja perekonnale. Tartu aja sisse jäi aga ka tutvumine Arbujate loominguga. „Luuletusi lugesin rohkem kui romaane,” on ta ise hiljem öelnud. 1937. aastal kaitses ta magistritöö pedagoogika alal. Asunud tööle Tartu Koduse Kasvatuse Instituuti, käis ta valdades kasvatusalaseid loenguid pidamas. 1939. aastal sündis perre esimene laps - poeg Tanel - ja kirjanduslik tegevus jäi emakohustuste ning peatselt alanud sõja tõttu kõrvale. 1944. aastal põgeneti Rootsi. Põgenemisteekonnast kõneleb Liidia jutustus „Laevavaras”, mis on avaldatud nii Rootsi Eesti Päevalehes (6. VIII 1975) kui ka „Mulkide almanakis” 1999. aastal. 1946. aastal sündis perre teine poeg Toomas. 1953. aastal kavatses Liidia Tuulse jätkata psühholoogiaõpinguid Stockholmi Ülikoolis, kus ta oli end täiendanud ka 1938. aastal, kuid loobus pärast aastapikkust ettevalmistuskursust plaanist, andes nii võimaluse abikaasale täielikuks pühendumiseks teadustööle. 1950. aastate algul asus Liidia Tuulse tööle sariteose „Sveriges Kyrkor” (Rootsi kirikud) toimetusse, kus ta koostas registreid.

1950. aastate teisel poolel tekkis Liidia Tuulsel uuesti soov katsetada luule tõlkimisega. Saksakeelsele luulele lisandus nüüd rootsi luuletajate looming. Tuulse tõlgitud autorite nimistu on pikk: Magda Bergquist von Mirbach, Karin Boye, Erik Lindegren, Anders Österling, Mare Kandre, Edith Södergran, Gunnar Ekelöf, Erik Axel Karlfeldt, Bo Bergman, Gottfried Benn, Hermann Hesse. Osa tõlgitud luuletustest avaldati 1960. aastatel Tulimullas ja ajalehes Teataja, osa jõudis 1990. aastatel Eesti Raadio luulesaadetesse. Kõige südamelähedasemaks kujunes Liidia Tuulsele Rainer Maria Rilke luule.

1940. aastate lõpul aktiviseerus pagulaseestlaste kultuurielu. Eesti kirjanikelt ilmus uusi raamatuid, üks viljakamaid autoreid oli Bernard Kangro. Alates 1950. aastast hakkas Kangro juhtimisel ilmuma ajakiri Tulimuld, 1951. aastal sai temast kirjastuse Eesti Kirjanike Kooperatiiv tegevdirektor.

1957. aastal avaldas Kangro koolipõlvemälestuste sugemeid sisaldava romaani „Sinine värav”. Selle peategelaseks on Eestist 1944. aastal põgenenud Olt (Fromhold Hagivang), kes elab Rootsis insener Ants Kibese nime all. Mälestuste äratajaiks on aga Rootsi turismireisile saabunud abikaasa ja peategelase nimekaimust onupoeg, kommunistlike vaadetega kirjanik. Oskar Kruus kirjutab: „Romaani eellugudeks olevate noorusmälestuste jutustamisel on sündmustikku lülitatud veel teine naistegelane Tiili, kellega Olt oli suhel- 
nud gümnaasiumiaastatel ning kellele koolilõpupeol armastustki avaldanud" (Kruus 2003: 65). Reaalsus seguneb irreaalsusega, nagu Kangro romaanidele omane. Üle järve ujudes kaob neiu peategelase silme all Pikkjärvest hoovavasse udusse ning upub, kuid ilmub mõni peatükk hiljem uuesti välja Tartus elava loodusteadlasena.

1950. aastate lõpul hakkas seni luuletõlgetega tegelnud Liidia Tuulse luuletama. Tema esimesed luuletused on eranditult lilledest: neid vaadeldes (taas)avastab ta maailma ja iseennast. Kulub mitu aastat, enne kui Liidia Tuulse need Bernard Kangrole arvustada saadab. Kangro kirjutab Hööris oma uut romaani („Emajõgi”). 23. I 1961 teatab Liidia Tuulse päevik Kangrolt tulnud postkaardist. Lilledega kaardi taga on tekst: „Emajõgi on küll kinni külmanud, aga lilled selle kaldal elavad muistegi, nagu näeme. B.”

Vastastikune postkaartide saatmine muutub ajapikku traditsiooniks. Ikka on need lilledega, nende taha kirjutatakse tervitusi, õnnitlusi või lühikesi mõistukõnelisi teateid ja hinnanguid loomingu kohta. Mingil ajal hakatakse teineteisele saadetud postkaartidele luuletusi kirjutama.

1961. aasta jaanuari keskel läheb Lundi teele uus luulekimp. Nende saatusest on juttu 16. II tehtud sissekandes: „Kui küsisin, kas nad on paranenud, siis vastab ta „Jah!” Kangro: Nüüd oleks aeg midagi sisse võtta, nüüd on neid palju. Mina: Ei! Parem võta mu tõlkeid, sellest tunneksin rõõmu.”

Kangro ei võta tõlkeid, vaid valib avaldamiseks luuletused „Talv”, „Talveunes”, „Esimene lumi”, „Sügisene tamm”. 23. III kirjutab Liidia Tuulse oma telefonijutuajamisest Kangroga lähemalt:

\section{„Mina: Kuidas julgen end seltskonnas näidata? \\ Kangro: Ära tee väljagi! \\ Mina: Sisult julgen küll. \\ Kangro: Vormi eest vastutan mina. \\ Kangro seletab, et kõik luule olevat intiimne. Ärgu ma võtku seda tõsiselt, et on piinlik."}

Kangro on see, kes õhutab Liidia Tuulset luuletamist jätkama. Nelikümmend aastat hiljem on Tuulse öelnud, et Kangrota ja koduakna all (Stockholmis Sköndali teel) oleva tammeta poleks temast luuletajat saanud (Viitol 1999: 639). Kangro huvi Liidia Tuulse luule vastu meenutab õpetaja huvi õpilase vastu. 1960. aastate algul soovitab ta: „Kirjuta kergeid värsse, kirjuta raskeid värsse, Tuglas ütles, iga pingutus tasub end ära. Kvantiteeti peab olema. Sa käid oma teed, nagu ütlesin. Pole tähtis, mis moodi, tähtis on resultaat, see jääb” (Liidia Tuulse päevik, 10. XII 1962). Kangro „katsetab” ja jagab teemasidki. 18. X 1966 kirjutatud päevikulehekülgedel seisab: „See oli ju Kangro, kes käskis kirjutada deemonitest Leviatan ja Mastema.” 10. XII 1962 on Kangro helistanud ja öelnud Liidiale: „Kirjuta tsükkel „Ball”. See olgu sulle tööülesanne.” „Balli” ei sünni, sünnib tsükkel „Vein”.

1958. aasta suvel sõitis Liidia Tuulse esimest korda koos perega puhkusele Ojamaale, kus Armin Tuulse uuris vanu kirikuid, Liidial aga avanes võimalus nautida saare looduse ilu. Liidia Tuulse sõnul tõi Ojamaa talle meelde Eesti. Ühes kunagises intervjuus on Liidia Tuulse kirjeldanud seda aega järgmiselt: „... sealne loodus on väga sarnane Eesti loodusele. Eriti taimestik. Kõik need nõiahambad, ussikeeled ja pajulilled tekitasid minus vaimustust ja 
äratundmist” (Viitol 1999: 639). Ojamaa toob meelde kodu ja lapsepõlve, siin sünnivad luuletused „Ma olen kodus”, „Uni uhab”, „Ubinheinad”, „Adru”, „Kloostriaias”, „Liiv õitseb”, „Ojamaa kirikus” I ja II jt luuletused. Fåröl käigust sünnib luuletus „Luited kui hanged”. Ojamaal veedetakse viisteist suve, aeg-ajalt viibitakse ka Ahvenamaal. Seejärel hakatakse puhkusi veetma Šveitsis.

1961. aasta kevadel, mil Liidia Tuulse esineb esimest korda Tulimullas luuletustega, peetakse Stockholmis Henrik Visnapuu 10. surma-aastapäeva. Šveitsist saabub Visnapuu-õhtule luulet lugema Õie Fleig-Tamm, kellega luuletaja tutvus Geislingeni põgenikelaagris. „Hõdele” ehk Õiele on pühendatud Visnapuu luulekogu „Rohtaed”. Õie Fleig-Tamm oli õppinud näitekunsti Liina Reimani juures, paguluses kujunes temast Henrik Visnapuu ja Marie Underi luule parimaid esitajaid, nende loomingu tutvustaja. 1961. aasta aprilli algul Stockholmi saabudes peatus ta Tuulsete juures. Koos veedetud nädal oli täis pikki vestlusi, luulet, muusikat ja tantsu. 13. aprillil on Liidia Tuulse päevikusse kirjutanud: „Oleme Õiega lugenud palju luulet. Rootslasi, sakslasi ja Kangrot. Õiega räägime Lõuna-Eesti murret. Mina mulgi ja tema Võru murret. On otsatult hubane ja kodune omma kiilt kõnelde. Sealjuures me naerame vahest pisarateni! [---] Õhtuti oleme kaua üleval ja siis on kontsert koos Toomaga. Armin mängib viiulit ja Toomas saadab. Õie aga tantsib balletti ja masurkat ja gavotti. Joome veini ja on väga pidulik olemine kuni öösel kella üheni.”

Liidia Tuulsel on pagulastest kultuurirahva hulgas palju häid tuttavaid ning sõpru, kuid 1959. aasta Šveitsi-reisil avastatud Õie Fleig-Tamm on see, kes on hingesugulane. Kui Õie ära sõidab, annab Liidia Tuulse talle lennukis lugemiseks kaasa Bernard Kangro „Jäälätted”. Õie Fleig-Tamm on kirjutanud selle raamatu esiküljele: „Mu süda on kõigest maailma sõprusest, armastusest täidetud. Sellel endaotsimise hingenädalal kingiti mulle tagasi mu vana elukannel kõigi mu südame viisidega. Kui see teraslind peaks hukkuma, ei karjata ma hirmust. Olen tänulik..."

1961. aasta kevad on ootamatult luulerikas. Seda tõendab ka 18. IV tehtud sissekande lõpp: „Täna on oivaline ilm. Kevade ja kaduvuse kontrast! See teeb ülemeelikuks! Milline laeva päev täna! Teel leidsin kibuvitsa põõsa, mis oli veel üleni punasid marju täis heleroheliste lehtede varjus." Marju täis kibuvits keset kevadvalgust muutub luuletuseks:

\section{Esimeses aprillisoojuses sa seisad lillade kaseraagude vahel ja kannad möödunud suve marjaraskust mida tuuled on peksnud ja parkinud külm näpistanud kuid linnud on jätnud puutumata.}

Kellele sa jagad möödunud suve rikkuse mida keegi ei näe keegi muu ei ihka kui uut sigivust tõotav maa.

Luuletus Liidia Tuulse päevikust. 
1961. aasta suvel Ojamaal viibides sai Liidia Tuulse kirja Arno Vihalemmalt, kes arvustab tema luuletusi. „Olin väga rõõmus selle spontaanse vastukaja puhul ja ma nagu kohkusin, et mind arvestatakse, et mu värsid on midagi reaalset," kirjutab Liidia Tuulse Õie Fleig-Tammele 5. VII 1962.

Sügisel jätkub „Sveriges Kyrkori” registrite tegemine. Töö tundub kohati igavavõitu, kuid 12. IV 1962 on päevikusse kirjutatud: „Ego sum lapis. Seda loen registrist. Seal on palju tarkust. Vahest teen registrit hoolega ja isegi rõõmuga. Eriti meeldib mulle isikuregister. Kui palju elusaatusi loen ma sealt. Tööd on palju, suur register peab lühikese aja jooksul valmis olema. Masinad ootavad!"

Registriga rööbiti valmivad kaks luuletust: „Virgeks veeks” ja „Päikesele vastu".

1962. aasta märtsi lõpul saadab Liidia Tuulse Marie Underile sünnipäevaks koos heade soovidega oma uue luuletuse „Lillehing”. Under vastab: „Tänan südamest rõõmustavalt üllatava õnnitluse eest kauni luuletuse näol! On väga liigutav, et mind meeles pidasite - ja veel nii üleval ja soojal viisil. Võiksite sagedamini avaldada oma värsse, tuues värskemat puhangut meil maad võtva dekadentsliku luule vastukaaluks" (Liidia Tuulse päevik, 2. IV 1962). Underi huvi Liidia Tuulse luule vastu on suur. Ta on üks esimesi, kes hakkab ka luulekogu kohta küsimusi esitama.

Kirjutada „käsib” ka Helmi Mäelo. Mäelo reageerib suure innu ja heameelega 1968. aastal ilmunud luulekogule „Liiv ja lumi”. Liidia Tuulse luule vastu tunneb ka elavat huvi Salme Raatma, kellega vahetatakse kirju. 14. I 1963 kirjutab Liidia Tuulse päevikus: „Ka Kangro sunnib kirjutama. Underile olevat Adson Wiedemanni sõnastikust sõnu otsinud. Under olevat rohkem linnainimene, sellepärast rohkem aialilli. Käskis saada Underist inspiratsiooni. See polevat epigoon."

1963. aasta märtsi lõpul toimub Marie Underi 80. sünnipäeva aktus. Järgmisel päeval kohtub Liidia Tuulse Kangroga. Minnakse Källssoni kohvikusse ning kõneldakse mitu tundi. Kangro on soovitanud Liidia Tuulsel koostada ettekanne lindudest Marie Underi luules. 7. III 1963 on Liidia Tuulse kirjutanud kohtumisest põhjalikumalt: „Ta vaatles mu väljakirjutusi Underi lindude üle ja andis nõu. [---] Tema „Kivisild” olevat valmis esimesest laastust. Järgmine romaan olevat „Linnutee” ühest hulkurist. Minu päevikut tagasi ei andvat. Ehk tulevat tarvis, „Nagu kõrberändurile lind paunas”. (Mul on olemas mu noorepõlve, üliõpilasaegne päevik. Minu ja Armini armastus paar aastat enne abiellumist. Sellest olin laenanud abikaasa teades kirjanikule lugemiseks kümmekond lehekülge. Et teaks, kuidas mõni tolleaegne üliõpilane oli. Kuulsin, et tema naistegelastele see tüüp ei sobinud. Aga hiljem sain need päevikuleheküljed tagasi. Armin arvas, et 100 aasta pärast on minu päevik harulduseks.) Õhtul helistas hotellist, et kuidas ma koju sain. „Kuidas elab su hing?” Vastus: „Hing on pulbriks jahvatatud elust”. See inspireeris luuletuse „Sinepiiva”.”

Suvel käis Liidia Tuulse koos abikaasaga Norra-reisil. Bergeni buss sõidab kaua mööda Drammeni jõe äärset teed. Sellest tekib kodus tagasi olles luuletsükkel „Drammen”. Aasta lõpul sünnivad uued, talveainelised luuletused. Need koos varem kirjutatutega lähevad teele Lundi poole. Aga mitte kõik. Liidia Tuulse kirjutab 12. I 1964 päevikusse: „Aga Jõuluimet ei saatnud, kuna see oli minu arvates liiga ilus.” Sügisel 1964 on Liidia Tuulse registri- 
tööst vaba ning kirjutab pika ettekande „Luuleelamusest”. Selles ütleb ta: „Luuletaja ei põgene tõelisusest, nagu on vahel väidetud. Otse vastupidi: luuletaja põgeneb tõelisusse. See on tõelisuse ihaldamine nii enesele kui ka teistele."

Nii „Linnud Marie Underi luules” kui ka „Luuleelamusest” on ettekanded, millega Tuulse käib ka aastaid hiljem erinevate organisatsioonide üritustel esinemas. Detsembri algul sõidab Liidia Tuulse „Luuleelamusega” Uppsalasse. Rongis kirjutab ta kaks uut luuletust: „Edvard Munch’i „Elutants”” ja „Elatud elu".

5. veebruaril 1965 saadab Marie Under Liidia Tuulsele kirja, milles on ka soovitus: „Kui teil juba on palju luuletusi päevikus tallel, siis toote ehk nad varsti ka päevavalgele - koguna.”

Luulekogu tegemise soovitused on õhus juba mitu aastat: 1964. aastal on sellest kõnelnud ka luuletaja, prosaist ja ajakirjanik Karin Saarsen.

1965. aasta toob aga kaasa süveneva mure seoses kodumaale jäänud ema haigusega. Liidia Tuulse otsustab eirata kodumaal käijate kritiseerijaid ning sõidab Eestisse. 18. X 1965 teatab päevik: „16. augustist 28. augustini olin kodus. Siis Tallinnas, Pärnus, Uulus ja Tartus. See oli elatud elu, kirjutatud minusse tulikirjaga."

Kangro on soovinud, et ta oma kodumaa reisist kirjutaks. 10. IX 1965 dateeritud kiri mõjub nagu terviklik looduselamus:

„Sa palusid küll suvisest udust kirjutada, aga seda polnud seal palju sel suvel. Aga Eestis nägin küll, kuidas udu tõusis niitude, põldude ja põõsaste kohal, kui olin teel Tartust Tallinna. Päike oli kogu aja meie ees uduvinas ja oli nagu suur läbipaistev apelsin või jälle nagu mõni hiigellatern. Kaks paralleelset triipu jooksid keskelt horisontaalselt läbi. Viimaks tõmbas õhtu kuuskede tumedad pitsist eesriided ette. Ka hommikust udu nägin rongiaknast. Paksu, trööstitut udu, kuid mis langes maha ja tõi imeilusa ilma. Küll kanarbik oli lilla ja punakaslilla ja pikk ja leegitsev. Ja palukad olid nagu punane riie mändide all Uulu rannas. Nägin kogu aja ja saja silmaga ja kuulasin saja kõrvaga. Kõik on talletatud mu aju varaaita, millest olen jaganud ja millele lõppu ei näi tulevat.

Nagu põhjatust varasalvest tuleb ikka ja jälle midagi päevavalgele. Sellest ei jõua kirjutada, seda peab rääkima.

Need paar nädalat kodus olen mõtetes olnud kogu aja Uulus, venna popsikohas ema ja vendade perekonna keskel. Seal võisin ilmsi olla kolm lühikest, kuid ometi nii pikka päeva ja ööd.

Pärnu on ööseti kõige kaunim kuurort, mida olen näinud.

Koidula platsil oitsesid valged floksid. Terve meri valgeid flokse. Ja öö oli soe, nagu 35 aastat tagasi. Vanade kaskede asemel on noored kased, aga juba suured puud, et mina ei märganud vahet. Küll nad olid valged noil augustiöödel.”

Kirja juurde kuulub ka luuletus „Rikkaim saak”, mille viimane stroof kõneleb kodumaal läbielatud uduelamusest. Kangro palve kirjutada udust saab tõeks. Uduigatsus kuulub noorusmälestuste aega: kaks aega ja „kaks loodust" lähevad segamini. Uduse maastiku reaalsus ja irreaalsus sulavad kirjas kokku müstilisemaltki kui luuletuses: kiri on nagu sild. Või - allikas silla juures? 
1967. aastal asub Liidia Tuulse luulekogu kokku panema. Talle tuleb appi Arno Vihalemm, kes on tema loomingu austaja ja arvustaja. Vihalemm paneb luulekogule pealkirja (Liidia Tuulse päevik 25. XI 1967) ja teeb ka kaanekujunduse. Liidia Tuulse esimene luulekogu on tundepuhas ja vahetu ning mõjub paradiisiaiana. Kui üks kriitik heidab luuletajale ette looduses ringi jalutamist, „mõtted õieti kusagil mujal”, haarab Arno Vihalemm sule ning kirjutab põhjaliku ja suurt tõsidust huumoriga vürtsitava retsensiooni, arvates, et ongi hea, kui luuletaja mõtted on kusagil mujal. Vihalemm kõneleb küpsemise valust, mis on "Liiva ja lume” peateema, tõstab esile autori ausust ja tema mõttekäigu uudsust: „...ta raamatus „valmimise valust” ei märkagi otseselt just seda valu nii väga, vaid rohkem valmimist kui fenomeeni...” (Vihalemm 1968: 252).

Liidia Tuulse järgmistes kogudes kerkib esile inimene, luuletustes tõusevad esile noorusmälestuste juurde kuuluvad märksõnad (järv, udu, mägi, puud, lilled, kivi, kiirgliblikas). Liidia Tuulse ja Bernard Kangro luuletuste vahelist dialoogi rõhutavad Kangro luuletustest pärit motod („Istuta puid”, „Habras kild”, „Sinine värav”, „Kimalane”, „Ärka üles”). Motosid on ka Rilke luuletustest. Üks luuletus on vormistatud Rilke ja Kangro kahekõnena („Rilket ja Kangrot lugedes”, 1978). Samal, 1978. aastal, kirjutab Liidia Tuulse Vänerni järve ääres pikema tsükli „Päevik haikudes” ja „Sügis Vänerni ääres”. „Värss võtab kuju” I ja II on selleks ajaks juba sündinud. Ja kuigi ta kirjutab: „Sõnadel on kiire / iga hetk võib hävitada elamuse” (Tuulse 2007: 149), jäävad elamused luules ellu - nagu mälestusedki. Luuletuses „Habras kild" (Tuulse 2007: 142) kirjutab Liidia Tuulse tänulikuna:

\author{
Mälestuste virmalised sähvivad \\ külma helki unelmaisse, \\ sähvivad tuliseid sädemeid unedesse. \\ Olgu kiidetud virmalised, \\ mis sundisid vaatama. \\ Ja nägema.
}

\title{
Arhiivimaterjalid
}

Liidia Tuulse päevik (eravalduses).

\section{Kasutatud kirjandus}

K a n g r o, Bernard 1990. Kogutud luuletusi. Aastaist 1927-1989. I köide. Lund: Eesti Kirjanike Kooperatiiv.

K a n g r o, Bernard 1992. Kipitai. Autobiograafiline romaan. Tallinn: Kupar.

Koolilinn Valga. Koguteos piltidega. Toimetanud Bernard Kangro, Raimond Kolk, Asta Lepik, Liidia Tuulse. Lund: Valga koolide õpilased, 1984.

Kr u u s, Oskar 2003. Bernard Kangro. Elukäik ja looming. Tallinn: Eesti Raamat. Tu u l s e, Liidia 1997. Muutuda sõnaks. Tallinn.

Tu u l s e, Liidia 2007. Kogutud luuletused 1969-1997. Tallinn: Eesti Keele Sihtasutus. 
Vi h a l e m m, Arno 1968. Küpsemise valust. - Tulimuld, nr 8, lk 248-252.

Vi it o l, Livia 1999. Viiskümmend viis aastat eestlasena Rootsis. Intervjuu luuletaja Liidia Tuulsega. - Keel ja Kirjandus, nr 9, lk 638-643.

\section{Becoming a Poetess: Liidia Tuulse's 100th Birthday}

Keywords: Estonian exile literature, the 1960s, Bernard Kangro, Marie Under, Arno Vihalemm, expatriate quest of identity, experience of nature as a catalyst of emotional memory

The article follows the poetic formation of the oldest living Estonian author Liidia Tuulse. The roles of Bernard Kangro, Helmi Mäelo, Marie Under, Arno Vihalemm, Õie Fleig-Tamm and others in that process are pointed out. The mutual relations of the expatriate authors, emergence of creative impulses and the phenomenally smooth evolution of Lidia Tuulse into a poetess are discussed.

Bernard Kangro's interest in Liidia Tuulse's poetic career was based on their shared school memories from Valga and a mystical South-Estonian sense of nature.

The talent of the young Liidia Tuulse was also noticed by Marie Under, whose supportive attitude enhanced her self-confidence. Projection of the emotions and experiences gained from her home landscapes to those of Sweden, Norway and Switzerland is part of the poetess's quest of identity. This quest culminates in her travel through Estonian nature and herself in the summer of 1965.

Livia Viitol (b. 1953), free-lance essayist and poetess, livia.viitol@mail.ee 